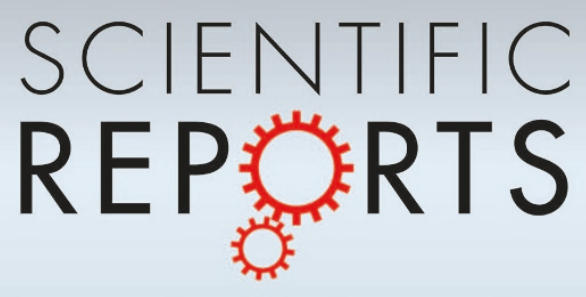

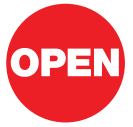

SUBJECT AREAS: CHEMICAL PHYSICS

COMPUTATIONAL CHEMISTRY

CARBON NANOTUBES AND

FULLERENES

NANOPARTICLES

Received

8 January 2013

Accepted

12 February 2013

Published

26 February 2013

Correspondence and requests for materials should be addressed to P.H. (huaiping@sinap. ac.cn); R.Q.Z. (aprqz@cityu.edu.hk) or Z.G.W. (wangzg@ jlu.edu.cn)

\section{Defect Induced Electronic Structure of Uranofullerene}

\author{
Xing Dai ${ }^{1}$, Cheng Cheng ${ }^{2}$, Wei Zhang ${ }^{2}$, Minsi Xin ${ }^{1,4}$, Ping Huai ${ }^{2}$, Ruiqin Zhang ${ }^{3,4}$ \& Zhigang Wang ${ }^{1,5}$
}

'Institute of Atomic and Molecular Physics, Jilin University, Changchun, 130012, P. R. China, ${ }^{2}$ Shanghai Institute of Applied Physics, Chinese Academy of Sciences, Shanghai 201800, P. R. China, ${ }^{3}$ Department of Physics and Materials Science and Centre for Functional Photonics (CFP), City University of Hong Kong, Hong Kong SAR, P. R. China, ${ }^{4}$ Beijing Computational Science Research Center, Beijing, P. R. China, ${ }^{5}$ State Key Laboratory of Theoretical and Computational Chemistry, Institute of Theoretical Chemistry Jilin University, Changchun, 130023, P. R. China.

The interaction between the inner atoms/cluster and the outer fullerene cage is the source of various novel properties of endohedral metallofullerenes. Herein, we introduce an adatom-type spin polarization defect on the surface of a typical endohedral stable $\mathrm{U}_{2} @ \mathrm{C}_{60}$ to predict the associated structure and electronic properties of $\mathrm{U}_{2} @ \mathrm{C}_{61}$ based on the density functional theory method. We found that defect induces obvious changes in the electronic structure of this metallofullerene. More interestingly, the ground state of $\mathrm{U}_{2} @ \mathrm{C}_{61}$ is nonet spin in contrast to the septet of $\mathrm{U}_{2} @ \mathrm{C}_{60}$. Electronic structure analysis shows that the inner $\mathrm{U}$ atoms and the $\mathrm{C}$ ad-atom on the surface of the cage contribute together to this spin state, which is brought about by a ferromagnetic coupling between the spin of the unpaired electrons of the $\mathrm{U}$ atoms and the $\mathrm{C}$ ad-atom. This discovery may provide a possible approach to adapt the electronic structure properties of endohedral metallofullerenes.

ndohedral metallofullerenes (EMFs) are novel fullerene derivatives that can encapsulate metal atom or even clusters in their inner space ${ }^{1,2}$. Previous studies show that the inner cluster and/or the outer cage of the unique structure preferentially adopt the stable closed-shell electronic configuration ${ }^{3,4}$, such as $\mathrm{La}_{2} @ \mathrm{C}_{72}{ }^{5}$, $\mathrm{La}_{2} @ \mathrm{C}_{80}{ }^{6,7}, \mathrm{Sc}_{2} @ \mathrm{C}_{66}{ }^{8}, \mathrm{Sc}_{2} \mathrm{C}_{2} @ \mathrm{C}_{68}{ }^{9}, \mathrm{Sc}_{3} \mathrm{~N} @ \mathrm{C}_{\mathrm{n}}(\mathrm{n}=68,78,80)^{10-13}, \mathrm{Ti}_{2} \mathrm{C}_{2} @ \mathrm{C}_{78}{ }^{14}$. There is a significant charge transfer between the metal atoms and the fullerene ${ }^{15,16}$. In EMFs, the internal metal atoms always donate electrons to the fullerene cage and carry considerable positive charges. This can result in an enhanced chemical reactivity as compared to the hollow fullerene ${ }^{1,2}$. EMFs have strong ability of donate and accept electrons, implying that they can be easily oxidized and reduced ${ }^{17}$. The stability of the whole system can be altered by this oxidation or reduction. The physical properties of EMFs strongly depend on the properties of the inner metal atom. Such a series of fantastic $M @ C_{n}$ structures have drawn extensive research interests in recent years. It is well known that defects can be easily formed in a large variety of carbon nanostructures, such as fullerenes, nanotubes and graphene. This defect can also bring about a significant change in the electronic structure as well as many other properties $^{18-20}$. But the natures of defective EMFs system are relatively unexplored till date. This work is aimed at gaining an understanding in this area through the study of an EMF structure with a typical spin polarized defective fullerene, which will be potentially beneficial in the design or synthesis of novel materials in several areas including catalysis and medicine $e^{21,22}$.

EMFs contain $\mathrm{U}, \mathrm{Th}, \mathrm{Pu}$ and other actinide elements are very important complexes. Actinide metallofullerene materials not only have the thermal stability of the fullerene-like, but also have the physicochemical properties of the actinide elements, and therefore it is foreseeable that they will have important potential application in advanced fuel technology. So, studies on EMFs containing $U$ atom have been widely reported. Guo et al. had prepared uranium fullerenes $\mathrm{U}_{\mathrm{C}} \mathrm{C}_{28}$ and $\mathrm{U} @ \mathrm{C}_{60}$ experimentally for the first time. $\mathrm{C}_{28}$ is usually unstable. The $\mathrm{U}$ atom wrapped into $\mathrm{C}_{28}$ stabilizes the fullerene cage ${ }^{23}$. Subsequently, Diener et al. synthesized U@ $\mathrm{C}_{74}$ and U@ $\mathrm{C}_{82}{ }^{24}$. Zhao and his co-workers successfully synthesized and isolated a new type of metallofullerene containing metal atoms of transuranic elements for the first time, proving that actinide metal atoms can stabilize the otherwise unstable $\mathrm{C}_{82}$ fullerene ${ }^{25}$, and explained the structural stability of $\mathrm{U}_{\mathrm{C}} \mathrm{C}_{82}$ through theoretical calculation of density functional theory $(\mathrm{DFT})^{26}$. The uranium dimer compound is a rare compound whose presence is evidenced only in experimental spectra ${ }^{27}$. Therefore, its theoretical study is scarce. Gagliardi and Roos have theoretically studied the $\mathrm{U}_{2}$ molecule using high-level ab initio method and found that this molecule contains three electron-pair bonds and four one-electron bonds, corresponding to a unique quintuple bond, and the $U_{2}$ molecule has a septet ground state ${ }^{28}$. Theorists have also predicted the possibility of fullerene encapsulating two $U$ 
atoms based on quantum first principles method. Usually, the exohedral dimetal fullerenes are more stable than the endohedral structures, e.g. $\mathrm{Cr}_{2}, \mathrm{Mo}_{2}$ and $\mathrm{W}_{2}{ }^{29}$. However, the $\mathrm{U}_{2}$ case is different. Its endohedral complex is significantly more stable than the exohedral and $\mathrm{U}_{2}$ lies at the center of the $\mathrm{C}_{60}$ fullerene ${ }^{29}$. The $\mathrm{U}-\mathrm{U}$ metal bond tends to dissociate and the $\mathrm{U}$ atoms interact with the inner wall of the cage when the neutral $\mathrm{U}_{2}$ molecule is encapsulated into carbon cage; but due to the special size of the $\mathrm{C}_{60}$ fullerene, the $\mathrm{U}-\mathrm{U}$ bond is weakened but not completely broken in the $\mathrm{U}_{2} @ \mathrm{C}_{60}$ EMF. The results from a DFT study using the GGA-PBE exchange correlation functional shows that the dimetalloendofullerene, $\mathrm{U}_{2} @ \mathrm{C}_{60}$, has an unprecedented U-U multiple bond consisting solely of sixfold ferromagnetically coupled one-electron-two-center bonds, which are dominated by the uranium $5 \mathrm{f}$ atomic orbitals, and it is septet in ground state ${ }^{30}$. This work opened up a new chemical field of the interaction between the actinide metal-metal bond and the fullerene, and provided the basis for many other studies. The size of the cavity can affect the properties of EMFs. If we enlarge the size to, say, $\mathrm{C}_{70}$ and $\mathrm{C}_{84}$, the metal-metal bond will be completely dissociated but the whole systems still have a septet ground state ${ }^{29}$.

Carbon nanostructures occurring in nature mostly contain defects, which cause changes in the electronic structure of carbon based nanomaterials and have been widely reported. However, fullerene is a necessary ingredient in EMFs. If the cage surface of the EMF which encapsulates $U_{2}$ molecule within it contains a defect, the nature of such a structure is expected to be much different. So, we have considered an adatom defect by introducing a carbon ad-atom over the $[6,6]$ bond on the typical $\mathrm{U}_{2} @ \mathrm{C}_{60}$ system and analyzed the features of this defective EMF $\mathrm{U}_{2} @ \mathrm{C}_{61}$.

\section{Results}

In order to examine the reliability of the exchange correlation (XC) functional and basis sets, we calculated the isolated $U_{2}$ molecule, the $\mathrm{C}_{60}$ fullerene and the EMF, $\mathrm{U}_{2} @ \mathrm{C}_{60}$. All the results qualitatively agree with the previous reports. Furthermore, the results showed that defective $\mathrm{C}_{61}$ has a triplet ground state. The adatom contributes significantly to the spin. The details for the calculations have been presented in the supplementary information Part 1.3.

In $\mathrm{C}_{61}$ fullerene, we have considered six isomers with the two uranium atoms at different positions. The full geometry optimization results showed that the total energy of the whole system is progressively reduced as a uranium atom gradually moves closer to the defect. Eventually, we found the structure $c$ in all isomers to be the most stable. Structure $\mathrm{c}$ can be characterized as one $\mathrm{U}$ atom located below the defect and another $U$ atom facing a six-ring as shown in Figure 1. The details for searching the lowest energy structure are provided in the supplementary information Part 2.

\section{Side view Top view}
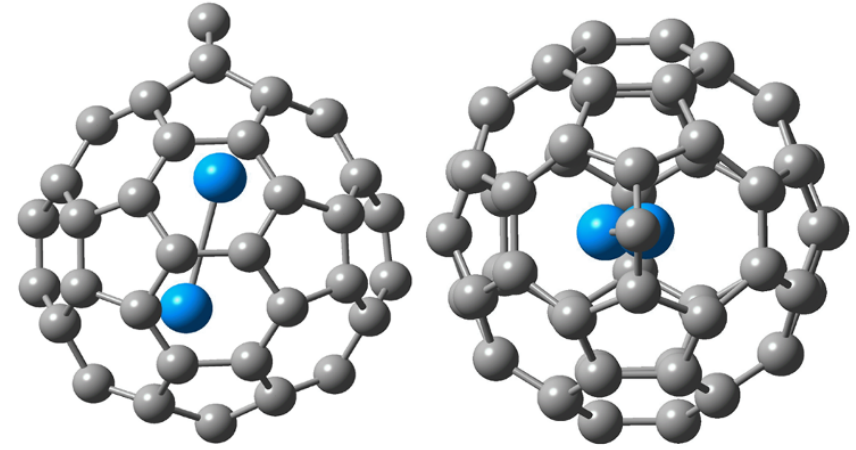

Figure 1 The equilibrium structure (Structure c) with the lowest energy of all the $\mathrm{U}_{2} @ \mathrm{C}_{61}$ isomers.
To investigate the possible mechanism responsible for the structural stability of c, we have proceeded systematically. First of all, a qualitative explanation is provided as follows. The single $U$ atom is reported to tend to adsorb on a hexagonal face from the inside when it is encapsulated in a carbon cage $\mathrm{e}^{26}$. The neutral $\mathrm{U}_{2}$ molecule is found to show a tendency to dissociate and also adsorb on the hexagonal faces in $\mathrm{C}_{60}$ fullerene $\mathrm{e}^{29,30}$. Interestingly, the adatom-type defect can enlarge the local size of the $\mathrm{C}_{60}$. We have calculated and compared the size of the $\mathrm{C}_{61}$ and $\mathrm{C}_{60}$. The diameter of $\mathrm{C}_{61}$ is about $0.31 \AA$ longer than the original $\mathrm{C}_{60}(\mathrm{Ih})$ along the direction of the defect. Moreover, the defect dissociates the original $[6,6]$ bond of the $\mathrm{C}_{60}$. Consequently, the distance between these two $\mathrm{C}$ atoms formerly forming the $[6,6]$ bond in the original $C_{60}$ increases by $0.79 \AA$. This causes the inner $U$ atom to sense the outer unsaturated ad-atom. Based on the discussion above, there is no doubt that both the size effect and the impact of the adatom directionally guide the motion of one of the two $U$ atoms to the defect area. As a result, the whole system is energetically favored to form the unique structure $c$ as depicted in Figure 1. The distance of the two $\mathrm{U}$ atoms in $\mathrm{C}_{61}$ fullerene (2.80 $\AA$ of BP86, $2.88 \AA$ of PBE0, see Table 1) is larger than the $\mathrm{U}_{2} @$ $\mathrm{C}_{60}$ case which has been calculated at the same level (2.70 $\AA$ of BP86, see supplementary information Part 1.3), including all the $\mathrm{U}_{2} @ \mathrm{C}_{60}$ results reported earlier $\left(2.72 \AA\right.$ of $\mathrm{PBE}^{30}, 2.73 \AA$ of $\left.\mathrm{BP} 86^{29}\right)$. This also confirms the conclusions of Gagliardi etc. ${ }^{29}$, that is, if the space around $\mathrm{U}_{2}$ in $\mathrm{U}_{2} @ \mathrm{C}_{\mathrm{n}}$ becomes larger, the two $\mathrm{U}$ atoms will tend to dissociate and interact with the inner wall of the cage ${ }^{29}$. It should be noted that, one of the adsorption sites of the two $\mathrm{U}$ atoms in $\mathrm{C}_{61}$ fullerene is different from that of $\mathrm{U}_{2} @ \mathrm{C}_{60}$, the $\mathrm{C}$ atoms in the defective area form a 10 -membered ring-like structure and a $\mathrm{U}$ atom shifts below the center of this 10-membered ring. This position is different from the case of $\mathrm{U}_{2} @ \mathrm{C}_{60}$ in which the two $\mathrm{U}$ atoms face the centers of two hexagonal rings. In this way, we have arrived at an interesting 'dissociation-adsorption' equilibrium state structure of neutral $\mathrm{U}_{2}$ molecule encapsulated in defective $\mathrm{C}_{61}$ fullerene. In Part 1.3 of the supplementary information, we have explained all the details of size comparison between $\mathrm{C}_{60}$ and $\mathrm{C}_{61}$ fullerenes.

Table 1 shows the full geometry optimization results of $\mathrm{U}_{2} @ \mathrm{C}_{61}$ (structure c) calculated at BP86/ANO_ECP60MWB 3-21G level and also with the PBE0 data as a test. From the energy relations of different electronic state we can see both the two XC functionals show that the nonet state is the most stable state and there is no imaginary frequency in the frequency calculation. Hence, structure $c$ is identified as the ground state structure and we express this electronic state as $\mathrm{U}_{2} @ \mathrm{C}_{61}\left(\mathrm{c},{ }^{9} \mathrm{~A}^{\prime}\right)$.

Since infrared (IR) and Raman spectroscopy have been widely used to characterize metallofullerenes1, we showed the IR and Raman spectrums of $\mathrm{U}_{2} @ \mathrm{C}_{61} \quad\left(\mathrm{c},{ }^{9} \mathrm{~A}^{\prime}\right)$ predicted at $\mathrm{BP} 86 /$ ANO_ECP60MWB $3-21 \mathrm{G}$ level in this paper. These results are expected to guide experimental research in this area. We first examined the infrared and Raman spectrums of the $\mathrm{C}_{60}$ and $\mathrm{U}_{2} @ \mathrm{C}_{60}$ and the results are consistent with the previous studies (see supplementary information Part 1.2). Also, we performed the same calculation for defective $\mathrm{C}_{61}$ fullerene. The IR-active vibrational mode in $\mathrm{C}_{61}$ is more complex than that in $\mathrm{C}_{60}$. Unique peaks due to the ad-atom appear in the IR spectrum at the frequencies of 1257.5 and

\begin{tabular}{|c|c|c|c|c|}
\hline System & Method & El. state & Total energy $(\mathrm{H})$ & $R_{U-U}(\AA)$ \\
\hline $\mathrm{U}_{2} @ \mathrm{C}_{61}$ (c) & BP86 & $\begin{array}{l}{ }^{7} A^{\prime} \\
{ }^{9} A^{\prime} \\
{ }^{11} A^{\prime} \\
{ }^{7} A^{\prime \prime} \\
{ }^{9} A^{\prime} \\
{ }^{11} A^{\prime \prime}\end{array}$ & $\begin{array}{l}-3265.91611 \\
-3265.91672 \\
-3265.89768 \\
-3262.79316 \\
-3262.79947 \\
-3262.78450\end{array}$ & $\begin{array}{l}2.77 \\
2.80 \\
2.79 \\
2.84 \\
2.88 \\
2.71\end{array}$ \\
\hline
\end{tabular}



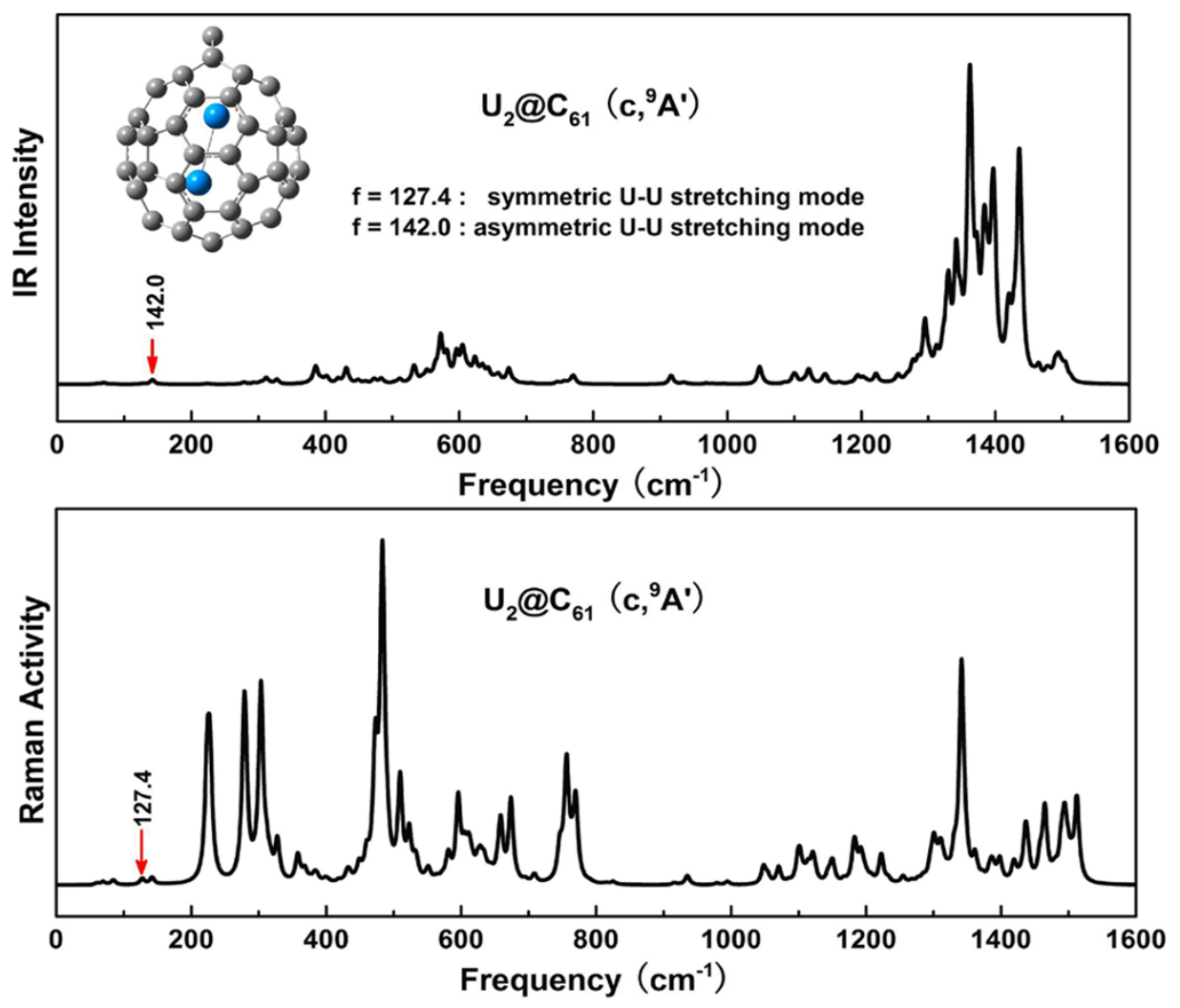

Figure $2 \mid$ Simulated IR and Raman spectrums of $\mathrm{U}_{2} @ \mathrm{C}_{61}\left(\mathrm{c},{ }^{9} \mathrm{~A}^{\prime}\right)$ at BP86/ANO_ECP60MWB 3-21G level.

$1353.6 \mathrm{~cm}^{-1}$. These vibrational modes correspond to the asymmetric and symmetric stretching modes of the two C-C bonds of the adatom respectively (see supplementary information Part 1.2).

Figure 2 shows the IR and Raman spectra of $\mathrm{U}_{2} @ \mathrm{C}_{61}\left(\mathrm{c},{ }^{9} \mathrm{~A}^{\prime}\right)$ respectively which are predicted at the BP86/ANO_ECP60MWB 3-21G level. We examined all the vibrational mode related to the $\mathrm{U}$ atoms and found that the symmetric U-U stretching mode is IRinactive but Raman-active. So, we can find this signal in the Raman spectrum at the frequency of $127.4 \mathrm{~cm}^{-1}$. This mode can suggest that there is still interaction between the two $U$ atoms in $\mathrm{C}_{61}$ fullerene, the special space size of $\mathrm{C}_{61}$ may not cause them to dissociate completely, although the distance between the two $\mathrm{U}$ atoms was enlarged in $\mathrm{C}_{61}$. The asymmetric $\mathrm{U}-\mathrm{U}$ stretching mode is IR-active and its weak intensity is predicted at a frequency of $142.0 \mathrm{~cm}^{-1}$. This mode explains the interaction between the $\mathrm{U}$ atoms and the inner wall of the cage. The unique IR-active peaks arising due to the adatom lie at the frequencies of 1327.5 and $1341.6 \mathrm{~cm}^{-1}$. The vibrational modes still correspond to the asymmetric and symmetric stretching modes of the two $\mathrm{C}-\mathrm{C}$ bond of the adatom respectively.

Furthermore, we compared the vibrational frequencies of $U$ atoms between $\mathrm{U}_{2} @ \mathrm{C}_{60}$ and $\mathrm{U}_{2} @ \mathrm{C}_{61}$ systems. From Table 2 we can clearly see that the relative frequency positions in the two EMF systems are reversed. The frequency of symmetric U-U stretching mode in $\mathrm{U}_{2} @$ $\mathrm{C}_{61}$ becomes significantly smaller than that in the $\mathrm{U}_{2} @ \mathrm{C}_{60}$. This

Table 2 | The frequencies of symmetric and asymmetric U-U stretching modes in $\mathrm{U}_{2} @ \mathrm{C}_{60}$ and $\mathrm{U}_{2} @ \mathrm{C}_{61}$ systems. All of these results were calculated at BP86/ANO_ECP60MWB 3-21G level

\begin{tabular}{lcc} 
System & Symmetric U-U stretching & Asymmetric U-U stretching \\
\hline $\mathrm{U}_{2} @ \mathrm{C}_{60}$ & 162.9 & 157.2 \\
$\mathrm{U}_{2} @ \mathrm{C}_{61}\left(\mathrm{c}{ }^{9} \mathrm{~A}^{\prime}\right)$ & 127.4 & 142.0 \\
\hline
\end{tabular}

interesting phenomenon illustrate that the bond between the two $\mathrm{U}$ atoms in $\mathrm{C}_{61}$ is very weak.

The key factor that governs the stability of EMFs is the magnitude of electronic charge transfer between the inner atom/cluster and the cage. Therefore, it is necessary to analyze its charge distribution. We have named the adatom as $C_{61 \text { th }}$, the $U$ atom close to the defect as $\mathrm{U}_{1 \mathrm{st}}$, and the other $\mathrm{U}$ atom as $\mathrm{U}_{2 \mathrm{nd}}$. We have particularly focused on the charge distribution on these three atoms and the relevant data is listed in Table 3. Usually, metal atoms in fullerene, including the $U$ atom, donate electrons to the cage and attain a considerable positive charge. Owing to the different equilibrium positions of the two $U$ atoms in the EMF $\mathrm{U}_{2} @ \mathrm{C}_{61}, \mathrm{U}_{1 \mathrm{st}}$ and $\mathrm{U}_{2 \text { nd }}$ also carry different amount of positive charges. In Table 3 , we observe that the $U_{1 s t}$ is more positively charged than the $U_{2 n d}$. It means that $U_{1 s t}$ which lies below the defect area transfers more electronic charge to the fullerene cage than the $U_{2 n d}$ which faces a six-member ring in the $C_{61}$ fullerene. This result can be explained as follows. The $U_{1 s t}$ adsorbs on a 10membered ring-like structure in contrast to the $U_{2 n d}$ which faces a hexagonal structure. $U_{1 s t}$ interacts with more $C$ atoms than the $U_{2 n d}$. As a result, it donates more electronic charge. The $\mathrm{C}$ atoms of the cage gather electronic charge from the inner $\mathrm{U}$ atoms and thus get negatively charged except the adatom. Both the two XC-functionals show that the $\mathrm{C}$ ad-atom transfers a small amount of

\begin{tabular}{|c|c|c|c|}
\hline System & Method & Atom & Charge (e) \\
\hline $\mathrm{U}_{2} @ \mathrm{C}_{61}\left(\mathrm{c},{ }^{9} \mathrm{~A}^{\prime}\right)$ & PBEO & $\begin{array}{l}C_{61 s t} \\
U_{1 s t} \\
U_{2 n d} \\
C_{61 s t} \\
U_{1 s t} \\
U_{2 n d}\end{array}$ & $\begin{array}{l}0.122 \\
2.383 \\
2.316 \\
0.181 \\
2.491 \\
2.410\end{array}$ \\
\hline
\end{tabular}




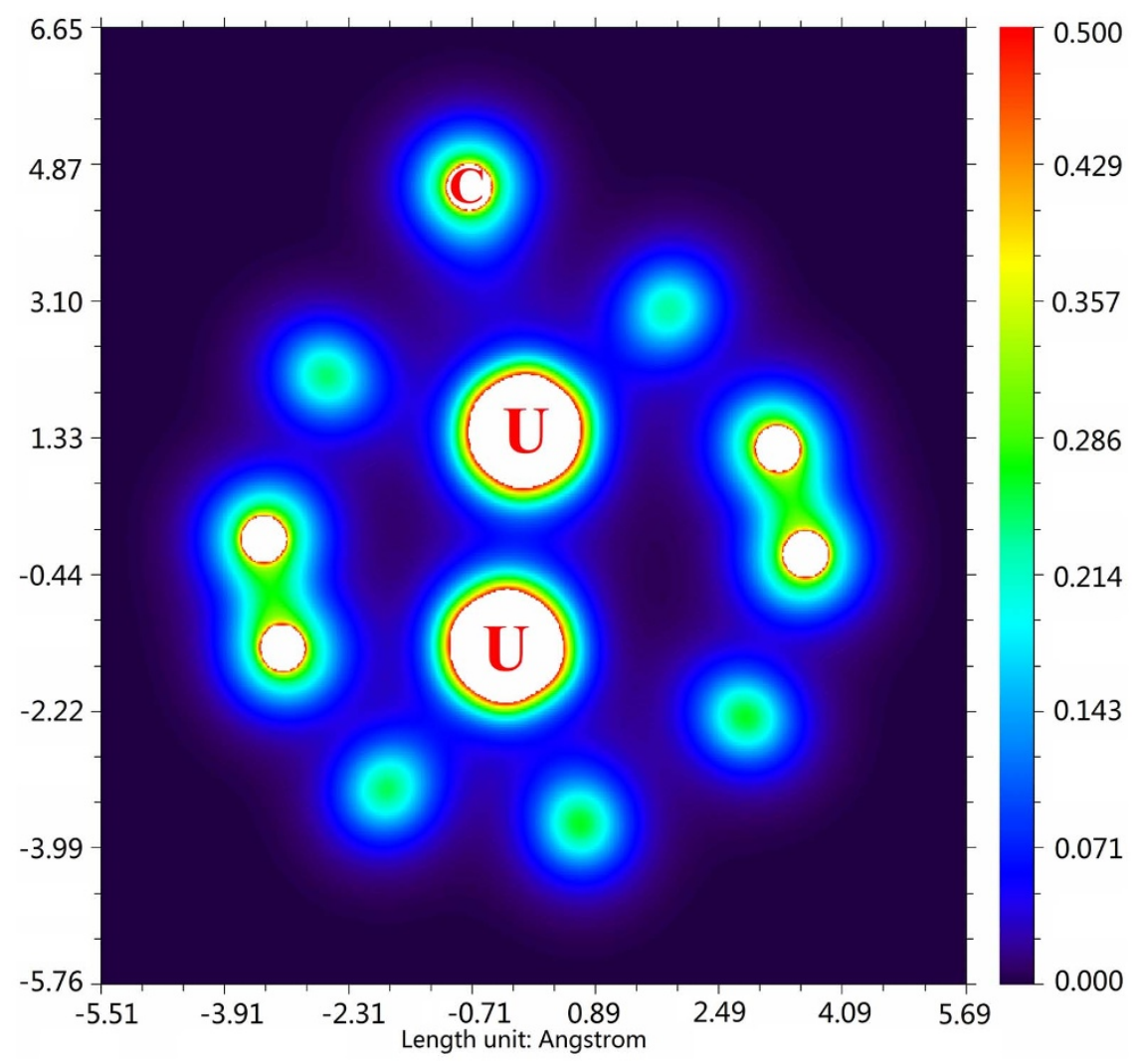

Figure $3 \mid$ The electron density color-filled map of $\mathrm{U}_{2} @ \mathrm{C}_{61}\left(\mathrm{c},{ }^{9} \mathrm{~A}^{\prime}\right)$.

electronic charge to the cage and acquires positive charge like the inner $\mathrm{U}$ atoms. The ten $\mathrm{C}$ atoms of the 10 -membered ring mentioned above are comparatively more negatively charged (about -0.297 ) than other $\mathrm{C}$ atoms on the cage, as they have gained electronic charge from both the inner $\mathrm{U}$ atom and the outer $\mathrm{C}$ adatom.

Electron density map shows the charge distribution in the system more clearly. In Figure 3, the region between the $\mathrm{U}$ atoms and the inner wall of the cage shows apparent electron density, suggesting obvious bonding interaction in these areas. The electron density in the space between the $\mathrm{U}_{1 \text { st }}$ and $\mathrm{C}_{61 \text { st }}$ is very low. We have also given the electron density contour line map of $\mathrm{U}_{2} @ \mathrm{C}_{61}\left(\mathrm{c},{ }^{9} \mathrm{~A}^{\prime}\right)$ as Figure $\mathrm{S} 6$ in the supplementary information in Part 1.3.

Molecular orbital (MO) analysis also helps us to understand the electronic structure. The multiplicity of the ground state of $\mathrm{U}_{2} @ \mathrm{C}_{61}$ is $\mathrm{M}=9$, which corresponds to eight unpaired electrons. So, we are concerned with the characteristics of LUMO $\alpha, \mathrm{HOMO} \alpha, \mathrm{HOMO} \alpha-1$ to $\mathrm{HOMO} \alpha-7$, which are singly-occupied frontier molecular orbitals of the $\mathrm{U}_{2} @ \mathrm{C}_{61}\left(\mathrm{c},{ }^{9} \mathrm{~A}^{\prime}\right)$. It can be seen from Figure 4 that the two $\mathrm{U}$ atoms provide significant contribution to all these orbitals. Due to impact of adatom-type defect on the fullerene, the shape of the

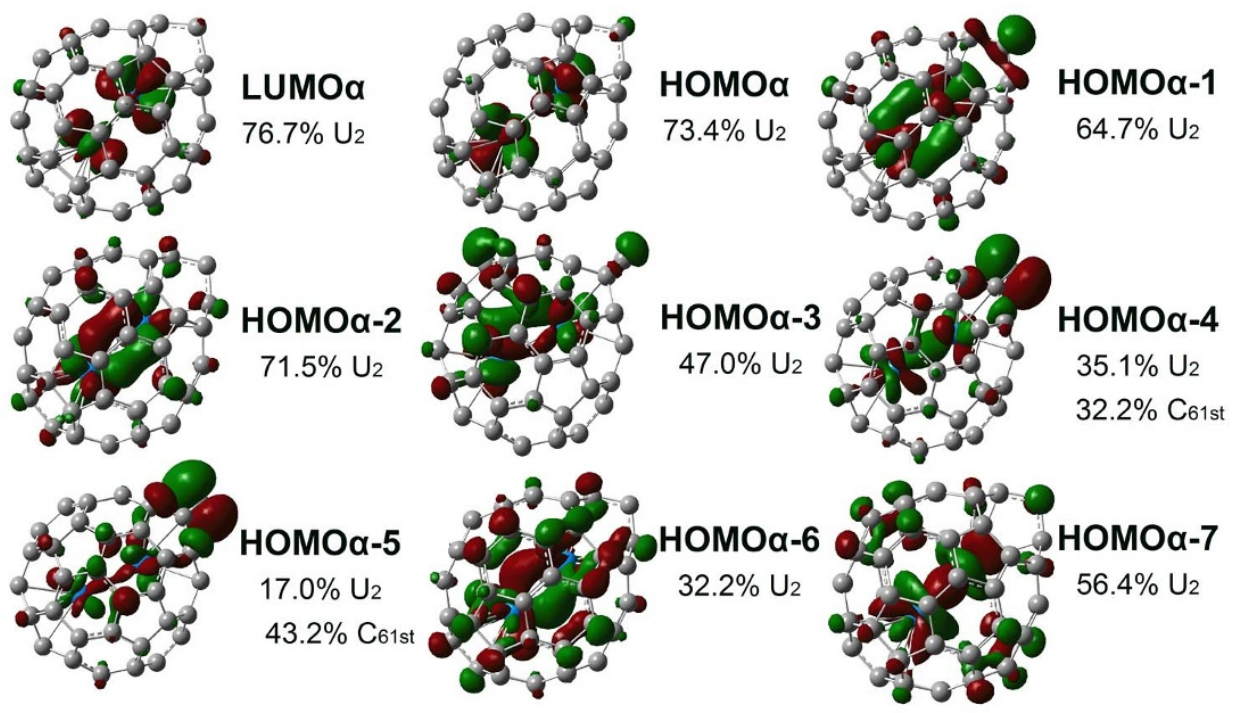

Figure $4 \mid$ The frontier molecular orbitals of the $\mathrm{U}_{2} @ \mathrm{C}_{61}\left(\mathrm{c},{ }^{9} \mathrm{~A}^{\prime}\right)$ at the isovalue of 0.03 . 
Table 4 | The percentages of atomic orbitals active in intermolecular interaction

\begin{tabular}{|c|c|c|c|c|c|c|}
\hline$U_{2} @ C_{61}\left(c,{ }^{9} A^{\prime}\right)$ & \multicolumn{2}{|c|}{$U_{1 s t}$} & \multicolumn{2}{|c|}{$\mathrm{U}_{2 \text { nd }}$} & \multicolumn{2}{|c|}{$\mathrm{C}_{61 \mathrm{st}}$} \\
\hline LUMO $\alpha$ & $50.59 \%$ & $0.03 \%$ & $25.35 \%$ & $0.16 \%$ & $0.03 \%$ & $0.57 \%$ \\
\hline $\mathrm{HOMO} \alpha-1$ & $40.01 \%$ & $1.17 \%$ & $22.54 \%$ & $0.18 \%$ & $1.15 \%$ & $6.30 \%$ \\
\hline $\mathrm{HOMO} \alpha-2$ & $29.94 \%$ & $0.31 \%$ & $40.72 \%$ & $0.23 \%$ & 0 & 0 \\
\hline$H O M O \alpha-3$ & $19.52 \%$ & $0.52 \%$ & $26.16 \%$ & $0.02 \%$ & $0.65 \%$ & $2.77 \%$ \\
\hline $\mathrm{HOMO} \alpha-6$ & $9.96 \%$ & $0.01 \%$ & $15.20 \%$ & 0 & 0 & $0.06 \%$ \\
\hline $\mathrm{HOMO} \alpha-7$ & $25.27 \%$ & $0.12 \%$ & $29.89 \%$ & $0.03 \%$ & $0.01 \%$ & $2.89 \%$ \\
\hline
\end{tabular}

orbitals localized on the $\mathrm{U}$ atoms has been deformed and no longer has any symmetry of $\mathrm{U}_{2} @ \mathrm{C}_{60}{ }^{30}$. Furthermore, we can obtain the natural atomic orbitals (NAO) from the density matrix. These NAOs can be understood as deformed atomic orbitals in the molecular structure. Molecular orbitals can be expanded by these NAOs, which are orthogonal to each other. So, we can calculate the sum of the square of the corresponding orbital coefficients as the contribution to these molecular orbitals. As the $5 \mathrm{f}$ and $6 \mathrm{~d}$ atomic orbitals of $\mathrm{U}$ atom are not fully occupied, they usually have a significant contribution to bonding. The $2 \mathrm{~s}$ and $2 \mathrm{p}$ orbitals are the valence orbitals of $\mathrm{C}$ atoms. These atomic orbitals are active in intermolecular interaction. Table 4 shows the contributions in the form of a percentage.

According to the shape of the MOs in Figure 4 and corresponding to the data in Table 4, all these MOs reflect the bonding between the two $\mathrm{U}$ atoms. The $\mathrm{HOMO} \alpha-4$ and $\mathrm{HOMO} \alpha-5$ reflect the contribution from the $2 \mathrm{p}$ electrons of the ad-atom. The $5 \mathrm{f}$ electrons of $\mathrm{U}$ atoms have a significant contribution to these frontier MOs but the contribution of $6 \mathrm{~d}$ shell is very small. These results show that the eight singly-occupied electrons mainly come from the 5 f of $U$ atoms and the $2 \mathrm{p}$ of the ad-atom.

We can directly find out the source of the contribution of the spin state from the spin density analysis. The ground state spin density analysis of $\mathrm{U}_{2} @ \mathrm{C}_{61}\left(\mathrm{c},{ }^{9} \mathrm{~A}^{\prime}\right)$ is shown in Figure 5. The ground state of the neutral $\mathrm{U}_{2}$ molecule is known to have a septet spin state. The six electrons of the same spin are contributed by the $5 \mathrm{f}$ orbital of the two $\mathrm{U}$ atoms. The ground state of $\mathrm{C}_{61}$ fullerene cages is triplet due to the existence of the defect, and the unpaired electron comes mainly from the $2 \mathrm{p}$ of the $\mathrm{C}$ adatom ( $\mathrm{spin}=1.82$, supplementary information Part 1.3). We can clearly see from Figure 5 that the nonet ground state of $\mathrm{U}_{2} @ \mathrm{C}_{61}$ mainly gets the spin contribution from both the $\mathrm{U}$ atoms and the adatoms. The unpaired electrons on the $\mathrm{U}$ atoms and the $\mathrm{C}$ ad-atom are of the same spin (the color of them are all blue). Calculated results show that the spin density of $U_{1 s t}$ is $3.09, U_{2 n d}$ of 3.30 and the adatom of 1.51. And also, there is a small amount of

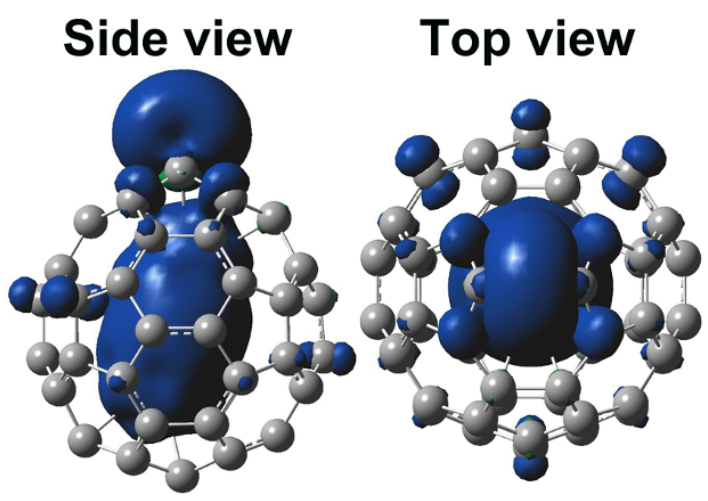

Figure $5 \mid$ The spin density distributions of the $\mathrm{U}_{2} @ \mathrm{C}_{61}\left(c,{ }^{9} \mathrm{~A}^{\prime}\right)$. spin contribution arising from the other $\mathrm{C}$ atoms of the fullerene cage. So, the reason of the nonet spin state is that there is a ferromagnetic coupling between the spin of the unpaired electrons of the $U$ atoms and the adatom.

\section{Discussion}

In summary, we have constituted an EMF of $\mathrm{U}_{2} @ \mathrm{C}_{61}$ structure through a spin polarization adatom-type defect on the surface of the typical dimetalloendofullerene $\mathrm{U}_{2} @ \mathrm{C}_{60}$. DFT theoretical calculations have shown that the defect could expand the local space within the $\mathrm{C}_{60}$ fullerene. This expanded local space and the electronic impact of the ad-atom directionally 'attract' one of the two $U$ atoms to the defect area. The bond length in $\mathrm{U}_{2}$ molecule elongates significantly in $\mathrm{C}_{61}$ fullerenes as compared to that of $\mathrm{U}_{2} @ \mathrm{C}_{60}$. From the vibrational spectra and molecular orbital analysis, bonding interactions are still observed between the two $U$ atoms in $\mathrm{C}_{61}$ fullerene, signifying that the expansion of the local space in the $\mathrm{C}_{60}$ cavity caused by the ad-atom defect does not dissociate the $\mathrm{U}_{2}$ molecule completely. Moreover, this EMF has a unique electronic state unlike the $\mathrm{U}_{2} @ \mathrm{C}_{60}$. The electronic ground state of $\mathrm{U}_{2} @ \mathrm{C}_{61}$ has a nonet spin multiplicity with a ferromagnetic coupling between the spin of the unpaired electrons of the $\mathrm{U}$ atoms and the adatom.

Because of its unique electronic structure, EMFs have very important promising applications in functional nanomaterials, biomedicines, etc. Our study found that we can further modify the equilibrium structure and electronic structure of EMFs by the introduction of spin polarization defect. This work will contribute to a profound understanding of the complex interplay between the inner metal atoms and outer surface of the fullerene cage in different defect-induced environments or conditions. It can pave possible new ways to regulate the electronic structure of the EMFs to realize its practical applications.

\section{Methods}

The relativistic effects and electron correlation must be taken into the consideration in a systematic investigation of actinide-containing systems. A significant advantage of DFT calculations is that accounting for the electron correlation does not increase the CPU time considerably. Therefore, DFT has been widely used in the calculation of actinides $^{31-34}$. Relativistic pseudopotential method is able to incorporate relativistic effects with a small increase in computational time $\mathrm{e}^{35,36}$. The impact of the pseudopotential core size of $U$ on chemical calculations based on DFT has been reported ${ }^{37,38}$ Previous studies show that pure DFT methods perform better than hybrid DFT or many-body perturbation methods in describing metal diatomics ${ }^{39-41}$, and therefore pure DFT, such as BP86 and PBE, was used in $\mathrm{U}_{2} @ \mathrm{C}_{60}$ studies $^{29,30}$. Based on the above, the gradient-corrected $\mathrm{BP} 86^{42} \mathrm{XC}$-functional was employed in this paper, and the hybrid functional $\mathrm{PBE}^{43,44}$ have also been used for a quality check. Based on testing results and analysis of the structure and charge population characteristics, 3-21G basis set ${ }^{45}$ was chosen for the carbon atoms ${ }^{46-50}$. Similarly, 3-21G basis set for $\mathrm{C}$ atoms of fullerene has been applied in a previous lanthanide EMFs study ${ }^{51}$. Scalar relativistic effects were applied to the uranium atoms. The (14s13p10d8f6g)/[6s6p5d4f $3 \mathrm{~g}]$ named $\mathrm{ANO}^{52}$ valence basis set and ECP60MWB ${ }^{52,53}$ pseudopotential basis set with 60 core-electrons were used. All the calculations have been performed in Gaussian 09 $\operatorname{program}^{54}$. 
2. Endofullerenes: A New Family of Carbon Cluster. (Eds: Akasaka, T., Nagase, S.), Kluwer Academic Publishers, 2002.

3. Fan, M., Lin, Z. \& Yang, S. Closed-shell electronic requirements for small fullerene cage structures. J. Mol. Struc. (THEOCHEM). 337, 231-240 (1995).

4. Fowler, P. W. \& Zerbetto, F. Charging and equilibration of fullerene isomers. Chem. Phys. Lett. 243, 36-41 (1995).

5. Kato, H., Taninaka, A., Sugai, T. \& Shinohara, H. Structure of a Missing-Caged Metallofullerene: $\mathrm{La}_{2} @ \mathrm{C}_{72}$. J. Am. Chem. Soc. 125, 7782-7783 (2003).

6. Shimotani, H. et al. Quantum Chemical Study on the Configuration of Encapsulated Metallons and the Molecular Vibration Modes in Endohedral Dimetallofullerene $\mathrm{La}_{2} @ \mathrm{C}_{80}$. J. Am. Chem. Soc. 126, 364-369 (2004).

7. Akasaka, T. et al. ${ }^{13} \mathrm{C}$ and ${ }^{139} \mathrm{La}$ NMR Studies of $\mathrm{La}_{2} @ \mathrm{C}_{80}$ : First Evidence for Circular Motion of Metal Atoms in Endohedral Dimetallofullerenes. Angew. Chem. Int. Ed. 36, 1643-1645 (1997).

8. Wang, C. R. et al. Materials science: $\mathrm{C}_{66}$ fullerene encaging a scandium dimmer. Nature 408, 426-427 (2000)

9. Shi, Z. Q., Wu, X., Wang, C. R., Lu, X. \& Shinohara, H. Isolation and Characterization of $\mathrm{Sc}_{2} \mathrm{C}_{2} @ \mathrm{C}_{68}$ : A Metal-Carbide Endofullerene with a Non-IPR Carbon Cage. Angew. Chem. Int. Ed. 45, 2107-2111 (2006).

10. Stevenson, S. et al. Materials science: A stable non-classical metallofullerene family. Nature 408, 427-428 (2000).

11. Olmstead, M. M. et al. Isolation and Structural Characterization of the Endohedral Fullerene $\mathrm{Sc}_{3} \mathrm{~N} @ \mathrm{C}_{78}$. Angew. Chem. Int. Ed. 40, 1223-1225 (2001).

12. Stevenson, S. et al. Small-bandgap endohedral metallofullerenes in high yield and purity. Nature 401, 55-57 (1999).

13. Campanera, J. M., Bo, C. \& Poblet, J. M. General Rule for the Stabilization of Fullerene Cages Encapsulating Trimetallic Nitride Templates. Angew. Chem. Int. Ed. 44, 7230-7233 (2005).

14. Cao, B. et al. EELS and ${ }^{13} \mathrm{C}$ NMR Characterization of Pure $\mathrm{Ti}_{2} @ \mathrm{C}_{80}$ Metallofullerene. J. Am. Chem. Soc. 123, 9679-9680 (2001).

15. Popov, A. A. \& Dunsch, L. Structure, Stability, and Cluster-Cage Interactions in Nitride Clusterfullerenes $\mathrm{M}_{3} \mathrm{~N} @ \mathrm{C}_{2 \mathrm{n}}(\mathrm{M}=\mathrm{Sc}, \mathrm{Y} ; 2 \mathrm{n}=68-98)$ : a Density Functional Theory Study. J. Am. Chem. Soc. 129, 11835-11849 (2007).

16. Valencia, R., Rodríguez-Fortea, A. \& Poblet, J. M. Chem. Commun. 4161-4163 (2007).

17. Suzuki, T. et al. Electrochemical properties of fullereneolanthanides. Tetrahedron 52, 4973-4982 (1996).

18. Xin, M. S. et al. Characteristic Vibrational Modes and Electronic Structures of Carbon Nanotubes Containing Defects. J. Phys. Chem. C 116, 292-297 (2012).

19. Boukhvalov, D. W. \& Katsnelsona, M. I. Defect-include ferromagnetism in fullerenes. Eur. Phys. J. B 68, 529-535 (2009).

20. Meyer, J. C. et al. Direct Imaging of Lattice Atoms and Topological Defects in Graphene Membranes. Nano Letters 8, 3582-3586 (2008).

21. Kang, S., Huynh, T. \& Zhou, R. Non-destructive Inhibition of Metallofullerenol Gd@C82(OH)22 on WW domain: Implication on Signal Transduction Pathway. Sci. Rep. 2, 957 (2012).

22. Shultz, M. D. et al. Encapsulation of a Radiolabeled Cluster Inside a Fullerene Cage, $\left.{ }^{177} \mathrm{LuxLu}_{3-\mathrm{x}}\right) \mathrm{N} @ \mathrm{C}_{80}$ : An Interleukin-13-Conjugated Radiolabeled Metallofullerene Platform. J. Am. Chem. Soc. 132, 4980-4981 (2010)

23. Guo, T. et al. Uranium Stabilization of $\mathrm{C}_{28}$ : A Tetravalent Fullerene. Science 257, 1661-1664 (1992)

24. Diener, M. D., Smith, C. A. \& Kirk Veirs, D. Anaerobic Preparation and SolventFree Separation of Uranium Endohedral Metallofullerenes. Chem. Mater. 9, 1773-1777 (1997)

25. Akiyama, K. et al. Isolation and Characterization of Light Actinide Metallofullerenes. J. Am. Chem. Soc. 123, 181-182 (2001).

26. Liu, X. et al. Theoretical Study on the Ground State Structure of Uranofullerene U@C 82 . J. Phys. Chem. A 116, 11651-116575 (2012).

27. Gorokhov, L. N., Emelyanov, A. M. \& Khodeev, Y. S. Mass-spectroscopic investigation of stability of gaseous $\mathrm{U}_{2} \mathrm{O}_{2}$ and $\mathrm{U}_{2}$. High Temp. 12, 1156-1158 (1974)

28. Gagliardi, L. \& Roos, B. Quantum chemical calculations show that the uranium molecule $\mathrm{U}_{2}$ has a quintuple bond. Nature 433, 848-851 (2005).

29. Infante, I., Gagliardi, L. \& Scuseria, G. E. Is Fullerene $C_{60}$ Enough to Host a Multiply Bonded Dimetal? J. Am. Chem. Soc. 130, 7459-7465 (2008).

30. Wu, X. \& Lu, X. Dimetalloendofullerene $\mathrm{U}_{2} @ \mathrm{C}_{60}$ Has a U-U Multiple Bond Consisting of Sixfold One-Electron-Two-Center Bonds. J. Am. Chem. Soc. 129, 2171-2177 (2007)

31. Kutepov, A. L. The effect of exact calculation of exchange interaction upon calculated electronic structure of actinides. J. Alloys. Compd. 444/445, 174-176 (2007).

32. Ingram, K. I. M., Tassell, M. J., Gaunt, A. J. \& Kaltsoyannis, N. Covalency in the $\mathrm{f}$ element-chalcogen bond. Computational studies of $\mathrm{M}[\mathrm{N}(\mathrm{EPR} 2)(2)](3)(\mathrm{M}=\mathrm{La}$, $\mathrm{Ce}, \mathrm{Pr}, \mathrm{Pm}, \mathrm{Eu}, \mathrm{U}, \mathrm{Np}, \mathrm{Pu}, \mathrm{Am}, \mathrm{Cm} ; \mathrm{E}=\mathrm{O}, \mathrm{S}, \mathrm{Se}, \mathrm{Te} ; \mathrm{R}=\mathrm{H}, \mathrm{Pr}-\mathrm{IPh}$ ). Inorg. Chem. 47, 7824-7833 (2008).

33. Wåhlin, P. et al. An Investigation of the Accuracy of Different DFT Fuctionals on the Water Exchange Reaction in Hydrated Uranyl(VI) in the Ground State and the First Excited State. J. Chem. Theory. Comput. 4, 569-577 (2008).

34. Lyon, J. T., Hu, H. S., Andrews, L. \& Li, J. Formation of unprecedented actinide $\equiv$ carbon triple bonds in uranium methylidyne molecules. Proc. Natl. Acad. Sci.USA. 104, 18919-18924 (2007).
35. Pyykkö, P. Relativistic effects in structural chemistry. Chem. Rev. 88, 563-594 (1988).

36. Dolg, M. Relativistic effective core potentials. Theor. Comput. Chem. 11, 793-862 (2002).

37. Iché-Tarrat, N. \& Marsden, C. J. Examining the Performance of DFT Methods in Uranium Chemistry: Does Core Size Matter for a Pseudopotential? J. Phys. Chem. A 112, 7632-7642 (2008).

38. Odoh, S. O. \& Schreckenbach, G. Performance of Relativistic Effective Core Potentials in DFT Calculations on Actinide Compounds. J. Phys. Chem. A 114, 1957-1963 (2010).

39. Yanasigava, S., Tsuneda, T. \& Hirao, K. An investigation of density functionals: The first-row transition metal dimmer calculations. J. Chem. Phys. 112, 545-553 (2000).

40. Barden, C. J., Rienstra-Kiracofe, J. C. \& Schaefer, H. F. Homonuclear 3d transition-metal diatomics: A systematic density functional theory study. J. Chem Phys. 113, 690-700 (2000).

41. Gutsev, G. L., Charles, W. \& Bauschlicher, J. Chemical Bonding, Electron Affinity, and Ionization Energies of the Homonuclear 3d Metal Dimers. J. Phys. Chem. A 107, 4755-4767 (2003).

42. Perdew, J. P. Density-functional approximation for the correlation-energy of the inhomogenous electron gas. Phys. Rev. B 33, 8822-8824 (1986).

43. Ernzerhof, M. \& Scuseria, G. E. Assessment of the Perdew-Burke-Ernzerhof exchange-correlation functional. J. Chem. Phys. 110, 5029-5036 (1999).

44. Adamo, C. \& Barone, V. Toward reliable density functional methods without adjustable parameters: The PBE0 model. J. Chem. Phys. 110, 6158-6170 (1999).

45. Binkley, J. S., Pople, J. A. \& Hehre, W. J. Self-consistent molecular orbital methods. 21. Small split-valence basis sets for first-row elements. J. Am. Chem. Soc. 102, 939-947 (1980).

46. Wilson, M. S. \& Ichikawa, S. Comparison between the geometric and harmonic mean electronegativity equilibration techniques. J. Phys. Chem. 93, 3087-3089 (1989).

47. Huzinaga, S., Sakai, Y., Miyoshi, E. \& Narita, S. Extended Mulliken electron population analysis. J. Chem. Phys. 93, 3319-3325 (1990).

48. Jakalian, A., Bush, B. L., Jack, D. B. \& Bayly, C. I. Fast, efficient generation of highquality atomic charges.AM1-BCC model: I. Method. J. Comput. Chem. 2, 132-146 (2000).

49. Cong, Y., Yang, Z. Z., Wang, C. S., Liu, X. C. \& Bao, X. H. Investigation of the regio- and stereoselectivity of Diels-Alder reactions by newly developed ABEEM $\sigma \pi$ model on the basis of local HSAB principle andmaximum hardness principle. Chem. Phys. Lett. 357, 59-64 (2002).

50. Yerushalmi, R., Scherz, A. \& Baldridge, K. K. Direct Experimental Evaluation of Charge Scheme Performance by a Molecular Charge-Meter. J. Am. Chem. Soc. 126, 5897-5905 (2004)

51. Jin, H. X. et al. Single Samarium Atoms in Large Fullerene Cages. Characterization of Two Isomers of Sm@ $\mathrm{C}_{92}$ and Four Isomers of $\mathrm{Sm@ \textrm {C } _ { 9 4 }}$ with the X-ray Crystallographic Identification of $\mathrm{Sm}_{\mathrm{C}_{1}}(42)-\mathrm{C}_{92}, \mathrm{Sm}_{\mathrm{s}}(24)-\mathrm{C}_{92}$, and Sm@ $\mathrm{C}_{3 \mathrm{v}}(134)-\mathrm{C}_{94}$. J. Am. Chem. Soc. 134, 10933-10941 (2012).

52. Cao, X., Dolg, M. \& Stoll, H. Valence basis sets for relativistic energy-consistent small-core actinide pseudopotentials. J. Chem. Phys. 118, 487-496 (2003).

53. Kuechle, W., Dolg, M., Stoll, H. \& Preuss, H. Energy-adjusted pseudopotentials for the actinides. Parameter sets and test calculations for thorium and thorium monoxide. J. Chem. Phys. 100, 7535-7542 (1994).

54. Frisch, M. J. et al. Gaussian 09, revision A. 01 Gaussian, Inc., Wallingford CT, 2009. See the supplementary information for full reference.

\section{Acknowledgements}

The work was supported by the National Basic Research Program of China Grant no. 2010CB934504, Strategically Leading Program of the Chinese Academy of Sciences Grant no. XDA02040100, the CAS Hundred Talents Program and Centre for Functional Photonics (CFP) of City University of Hong Kong. Z.W. acknowledges the High Performance Computing Center (HPCC) of Jilin University and NSFC Nos. 11004076

\section{Author contributions}

X.D. performed most of the numerical simulations. Z.G.W. and X.D. carried out most of the theoretical analysis. C.C., W.Z. and M.S.X. carried out some numerical simulations and theoretical analysis. Z.G.W., P.H. and R.Q.Z. contributed most of the ideas and wrote the paper. All authors discussed the results and commented on the manuscript.

\section{Additional information}

Supplementary information accompanies this paper at http://www.nature.com/ scientificreports

Competing financial interests: The authors declare no competing financial interests

License: This work is licensed under a Creative Commons

Attribution-NonCommercial-NoDerivs 3.0 Unported License. To view a copy of this license, visit http://creativecommons.org/licenses/by-nc-nd/3.0/

How to cite this article: Dai, X. et al. Defect Induced Electronic Structure of Uranofullerene. Sci. Rep. 3, 1341; DOI:10.1038/srep01341 (2013). 